\title{
Curso del Departamento de Ciencias Básicas
}

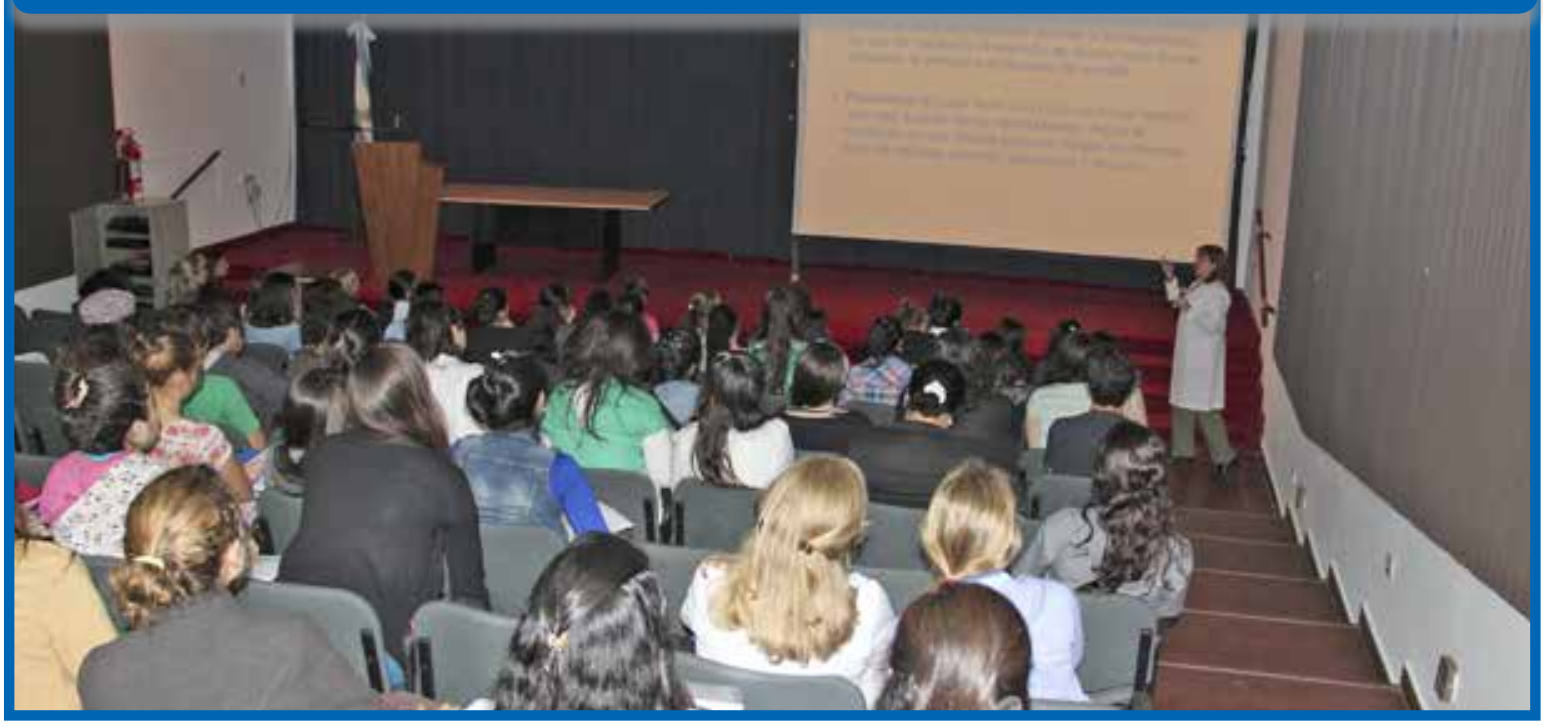

En el marco de Cursos de Actualización orEganizados por la Secretaria de Extensión, se realizó el curso "Pulpa dentaria. Actualización desde un enfoque multidisciplinar" en el que participaron como dictantes profesores de las asignaturas disciplinares que conforman el Departamento de Ciencias Básicas de la Facultad de Odontología. UNNE.

El curso fue pensado para brindar actualización a estudiantes, docentes y graduados sobre el tejido pulpar teniendo en cuenta los nuevos adelantos sobre estudios histoquímicos, ingeniería tisular y la potencialidad de diferenciación relativamente amplia de sus células que pueden ofrecer importantes contribuciones en el campo de la regeneración de los tejidos.

El desarrollo se realizó desde una revisión morfohistofuncional abordando luego el comportamiento del tejido pulpar bajo la acción de diversos agentes físicos-químicos y bacterianos, pasando por los síntomas que desencadenan y los signos que contribuyen al diagnóstico clíni-

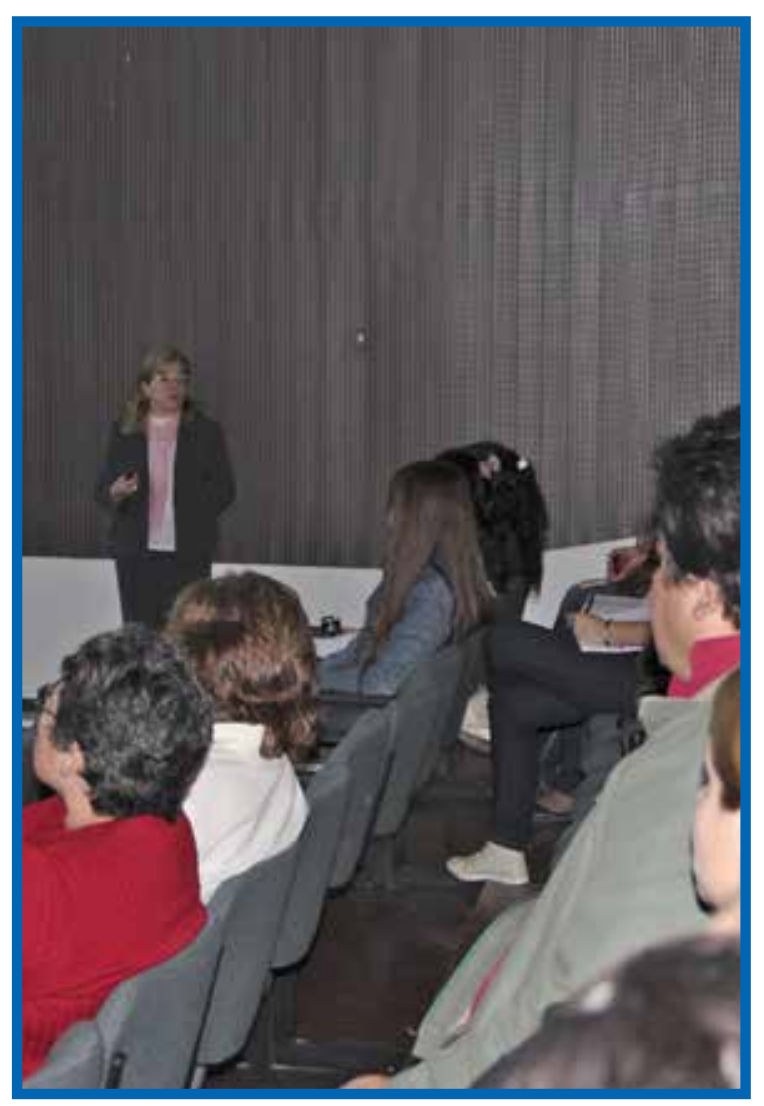




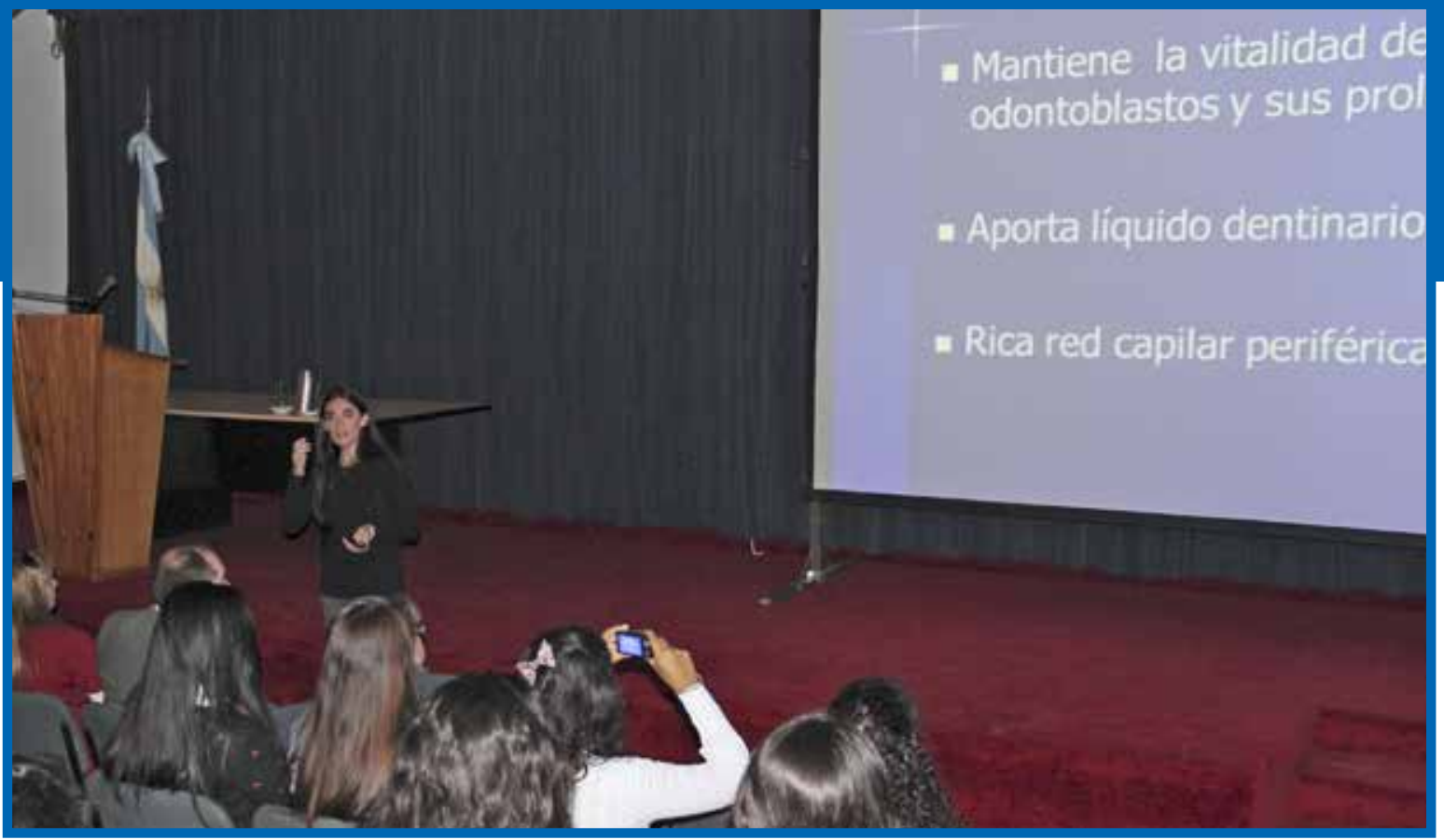

co e histopatológico, contenidos fundamentales que dieron la base para la comprensión de la capacidad que conservan las células de la pulpa, para ser consideradas en los trabajos de investigación de la última década, como células madres. La extracción sencilla, no invasiva para la obtención del tejido pulpar en dientes temporarios y permanentes sanos, podría ser la oportunidad para la diferenciación y regeneración de diversos tejidos.

Participaron como dictantes profesores de la asignatura Introducción a la Odontología, Prof. María Adelina Guiglioni y Gabriela Guadalupe Bessone; Prof. María Hortensia Frank de la asignatura Anatomía General; Prof. Bertha Val-
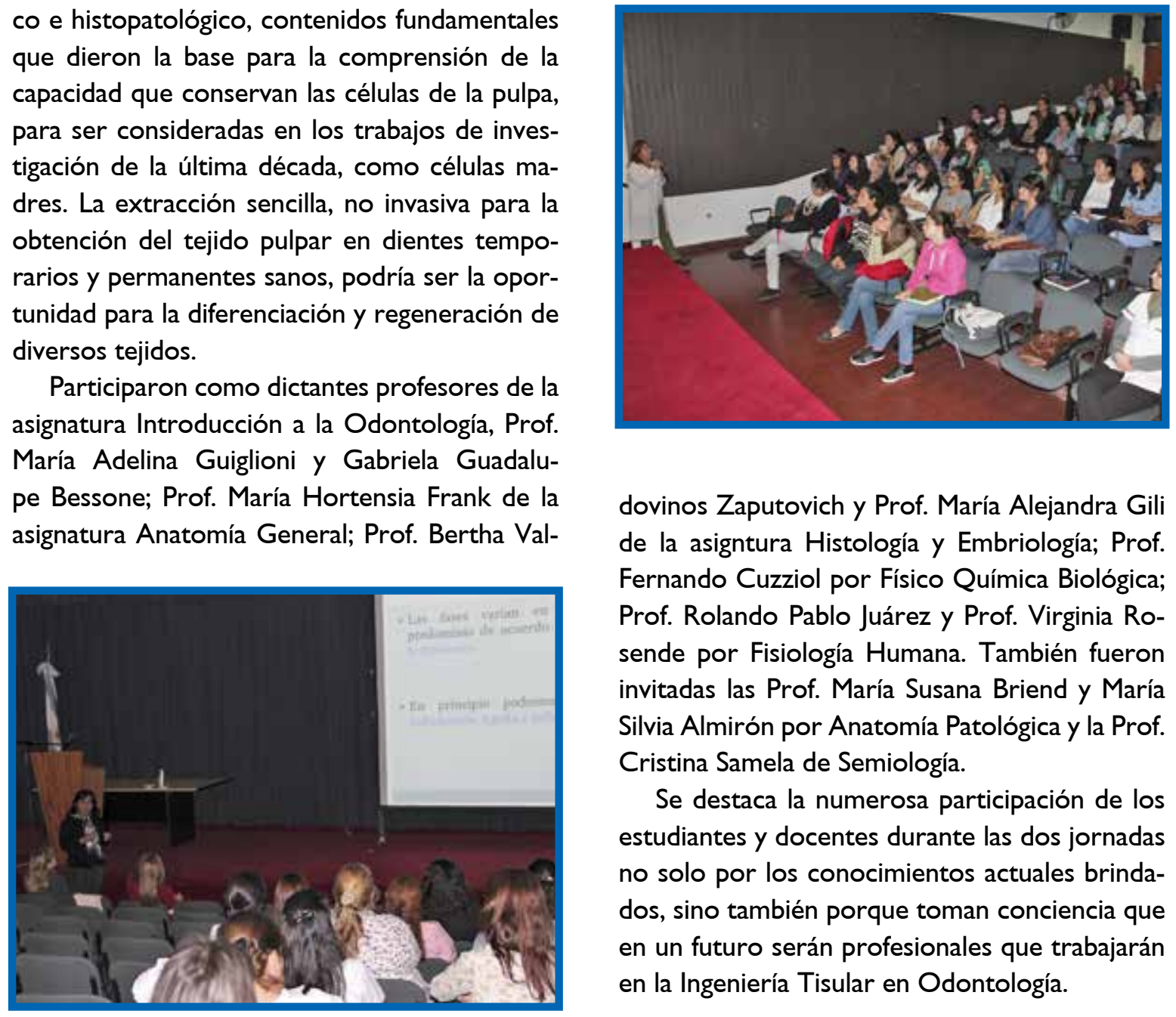

dovinos Zaputovich y Prof. María Alejandra Gili de la asigntura Histología y Embriología; Prof. Fernando Cuzziol por Físico Química Biológica; Prof. Rolando Pablo Juárez y Prof. Virginia Rosende por Fisiología Humana. También fueron invitadas las Prof. María Susana Briend y María Silvia Almirón por Anatomía Patológica y la Prof. Cristina Samela de Semiología.

Se destaca la numerosa participación de los estudiantes y docentes durante las dos jornadas no solo por los conocimientos actuales brindados, sino también porque toman conciencia que en un futuro serán profesionales que trabajarán en la Ingeniería Tisular en Odontología. 